Correction

\title{
Correction: Salgado Delgado, M.A., et al. Comparative Life Cycle Assessment of a Novel Al-Ion and a Li-Ion Battery for Stationary Applications. Materials 2019, 12, 3270
}

\author{
Mario Amin Salgado Delgado ${ }^{1, * \mathbb{C}}$, Lorenz Usai ${ }^{1}$, Linda Ager-Wick Ellingsen ${ }^{1}$, Qiaoyan Pan ${ }^{2}$ \\ and Anders Hammer Strømman ${ }^{1}$ \\ 1 Industrial Ecology Program, Norwegian University of Science and Technology, E1-Høgskoleringen 5, \\ 7491 Trondheim, Norway; lorenzo.usai@ntnu.no (L.U.); linda.ellingsen@asplanviak.no (L.A.-W.E.); \\ anders.hammer.stromman@ntnu.no (A.H.S.) \\ 2 ACCUREC Recycling GmbH, Bataverstraße 21, DE-47809 Krefeld, Germany; qiaoyan.pan@accurec.de \\ * Correspondence: amin.salgado@ntnu.no
}

Received: 7 November 2019; Accepted: 21 November 2019; Published: 25 November 2019

The authors wish to make the following corrections to this paper [1]: We have omitted the contribution of the co-author Dr. Linda Ager-Wick Ellingsen.

The authors would like to apologize for any inconvenience caused to the readers by this change.

\section{Reference}

1. Salgado Delgado, M.A.; Usai, L.; Pan, Q.; Strømman, A.H. Comparative Life Cycle Assessment of a Novel Al-Ion and a Li-Ion Battery for Stationary Applications. Materials 2019, 12, 3270. [CrossRef]

(C) 2019 by the authors. Licensee MDPI, Basel, Switzerland. This article is an open access article distributed under the terms and conditions of the Creative Commons Attribution (CC BY) license (http://creativecommons.org/licenses/by/4.0/). 